\title{
Human Mobility in the Sendai Framework for Disaster Risk Reduction
}

\author{
Lorenzo Guadagno ${ }^{1}$
}

Published online: 4 March 2016

(c) The Author(s) 2016. This article is published with open access at Springerlink.com

\begin{abstract}
This article looks at how population movements are addressed by the Sendai Framework for Disaster Risk Reduction 2015-2030 (SFDRR), and highlights some of the potential implications of the SFDRR on disaster risk reduction (DRR) and mobility management work. The article looks at the operational implications of the SFDRR text and covers issues of including migrants in DRR work; informing urban development about current and future mobility trends; managing relocations, evacuations, and displacement to prevent future risks and reduce existing ones; and preparing for and managing disaster-induced population movements to reduce the direct and indirect impacts of natural hazards. Overall, the references to human mobility within the SFDRR show an evolution in the way the issue is considered within global policy dialogues. Both the potential of population movements to produce risk and their role in strengthening the resilience of people and communities are now clearly recognized. This is an evolution of previously prevailing views of mobility as the consequence of disasters or as a driver of risk. While some implications of the DRR-mobility nexus might still be missing from DRR policy, population movements are now recognized as a key global risk dynamic.
\end{abstract}

Keywords Disaster risk reduction - Displacement . Human mobility · Migration - Relocation ·

Sendai framework for disaster risk reduction

Lorenzo Guadagno

lguadagno@iom.int

1 Department of Operations and Emergencies, International Organization for Migration (IOM), 1200 Geneva, Switzerland

\section{Introduction}

In March 2015, the United Nations (UN) Member States signed the Sendai Framework for Disaster Risk Reduction 2015-2030 (SFDRR) (UNISDR 2015a) at the Third World Conference on Disaster Risk Reduction in Sendai, Japan. In June 2015, the document was formally adopted by the UN General Assembly, and stands now as the global blueprint for all efforts aiming to reduce the impacts of hazards on people, communities, and societies over the next 15 years.

The post-2015 disaster risk reduction (DRR) dialogue that culminated in the Sendai conference and in the SFDRR took place in the context of a broader process of global policy reform. In September 2015, a set of new sustainable development goals (SDGs) was agreed upon (UN 2015a). In December 2015, negotiations aiming to establish global mechanisms for climate change mitigation and adaptation reached a major milestone with the Adoption of the Paris Agreement (UN 2015b) at the 21st Conference of the Parties of the United Nations Framework Convention on Climate Change (UNFCCC). The process towards the first World Humanitarian Summit is underway and should culminate in the May 2016 event with a new set of commitments and actions in support of communities facing humanitarian needs. ${ }^{1}$ A new agenda to address well-being challenges and seize development opportunities embedded in urbanization and urban governance should be agreed upon by October $2016 .^{2}$

All these processes have a certain degree of overlap as they confront some of the core features and trajectories of modern societies and development. Coordination among the various tracks and their outcomes has been highlighted

\footnotetext{
${ }^{1} \mathrm{http}: / /$ worldhumanitariansummit.org.

2 https://www.habitat3.org.
} 
as one of the critical issues for the design, development, and implementation of the upcoming global policy system (Kelman 2015). Some attempts have been made to acknowledge efforts in parallel tracks, and to try to promote consistency among them-see, for example, references to the SFDRR in the SDG outcome document (UN 2015a, target 11.b) and in the preamble of the Paris Agreement (UN 2015b). However, it is still uncertain whether the different processes will actually result in a coherent, mutually reinforcing set of objectives, mechanisms, and means of implementation.

All these processes have recognized the importance of issues linked with population movements. Today's unprecedented population flows, involving around 1 billion people migrating within and across borders (UNDP 2009; UNDESA 2013), tens of millions displaced by disasters and conflicts (IDMC n.d.), and many more people moving shorter distances and on a temporary basis (Tacoli 2013), are a key feature of modern, globalized societies (Castles and Miller 2009). To different extents, all these processes have highlighted and captured the complex implications of such movements for global well-being and risk-the access to opportunities and resources they open up, the circulation of ideas and wealth they underpin, and the exposure to new and increased hazards they can result in for those moving, as well as their home and their host communities (for an overview of disaster risk implications of population movements see IOM 2015a).

This might have been particularly apparent in the progress of the DRR dialogue leading to the Sendai conference. The only reference to population movements included in the Hyogo Framework for Action 2005-2015 (HFA) (UNISDR 2005) was paragraph 19.i. It recognized that forced population movements (whether induced by disasters or conflicts) and efforts to address them can result in hazard exposure and vulnerability, and called for the management of their risk outcomes. In contrast, the discussions on the successor framework to the HFA covered a variety of mobility-related topics, including displacement, relocations, migration and migrants' specific conditions of vulnerability, as well as remittance transfers and, more in general, migrants' contribution to resilience.

While all these issues appeared to be highly sensitive, the final SFDRR text integrates several elements of these discussions and reflects a nuanced view of population movements as a dynamic that can result in increased or reduced hazard impacts. However, the text does not explicitly address a number of mobility-related issues that are fundamental to risk creation and reduction processes, such as the role internal and international migration policies play in shaping people's exposure and vulnerability, the centrality of remittance transfers and household-level translocal networks to individual and collective resilience- building, and the need to address displacement situations to reduce direct and indirect consequences of disasters.

That such a complex discourse has at least partly taken hold in the SFDRR is the result of an increasing understanding of, and attention to, human mobility trends, features, and outcomes within academic and policy work on mobility, development, and the environment. This may represent the foundation for future policy, and scientific and operational efforts to address this complexity in a more systematic manner. However, the more articulated reflection on this complex issue may come at the price of reduced clarity; some of the indications given by the SFDRR point to a variety of different implementation options. This article aims to contribute to upcoming DRR efforts by analyzing how human mobility is mentioned in the SFDRR text and what the implications are of the various references to the design and implementation of concrete policies and programs.

\section{Methodological Note}

The observations included in this article are based on the author's direct participation in the SFDRR consultation and drafting process. They build upon the reading of the various iterations of the SFDRR text (in particular its pre-zero ${ }^{3}$ and zero drafts ${ }^{4}$ ), the review of a diverse body of academic literature (particularly on the topics of migration and development, and environment and migration), and the analysis of the operational efforts carried out by the International Organization for Migration (IOM) and other actors in preparing for, managing, and addressing displacement, managing relocations, and facilitating circular migration and returns for risk reduction purposes (IOM 2013). The categorization of human mobility issues into the five areas proposed below has emerged as part of advocacy efforts by the IOM and its partners in the lead-up to the Sendai conference, and has been used repeatedly to articulate the organization's policy discourse on DRR.

Much of this work has used the concept of "human mobility" to refer to the full spectrum of population movements-whether voluntary or forced, assisted or spontaneous, long- or short-term, and long- or short-distance. This is central to analytical efforts that look at population movements as a dynamic of risk reduction and creation-a perspective that is particularly productive for DRR work (IOM 2015a). Throughout this article the term "human mobility" is used with this meaning to help

\footnotetext{
${ }^{3}$ http://www.wcdrr.org/documents/wcdrr/Pre-zero_draft_post2015_ frmwk_for_DRR_8_August.pdf.

${ }^{4}$ http://www.un.org/disabilities/documents/events/wcdrr/zero_draft. pdf.
} 
articulate a consistent discourse, referring to its specific manifestations (for example, migration, displacement) when needed.

\section{Including Migrants in the Design and Implementation of DRR}

The final text of the SFDRR includes three references to articulate the need to include migrants in disaster risk reduction and management work at all level:

Paragraph 7: governments should engage with relevant stakeholders, including [...] migrants $[\ldots]$ in the design and implementation of policies, plans and standards (UNISDR 2015a, p. 10).

Paragraph 27(h): empower local authorities, as appropriate, through regulatory and financial means to work and coordinate with [...] migrants in disaster risk management at local level (UNISDR 2015a, p. 18).

Paragraph 36(a)(vi): Migrants contribute to the resilience of communities and societies and their knowledge, skills and capacities can be useful in the design and implementation of disaster risk reduction (UNISDR 2015a, p. 23).

These paragraphs are based on the understanding that migrants are a key component of modern societies. They represent a significant share of the global population (at least $14 \%$, based on the UN estimates on international and national migrants indicated above), and a much bigger share of the population of some of the world's key economic and cultural hubs-for example, about $40 \%$ in Auckland, NZ and Rotterdam, the Netherlands, including only international migrants and their children, or over $30 \%$ in Buenos Aires, including internal and international migrants (Juzwiak et al. 2014).

Experience has shown that migrants often present specific patterns of vulnerability in the face of disasters, linked to language and cultural barriers, lack of local knowledge (including hazard awareness), reduced availability of social networks, physical and social marginalization, and legal obstacles to accessing relief and recovery assistance (Koser 2014; Weerasinghe and Taylor 2015). At the same time, migrants do play a role in the circulation of material and immaterial resources that underpin economic well-being, cultural vitality, and resilience of households, communities, and societies (IOM 2015a), and therefore need to be considered as a specific group of DRR stakeholders.

Neither of these attributes is an exclusive result of movement across international borders. In a number of geographical contexts, internal migrants are likely to experience language, administrative, and cultural barriers that result in conditions of marginalization, hazard exposure, and vulnerability not unlike those of international migrants (IOM 2015b). At the same time, access to a diverse pool of opportunities, resources, and networks, risk diversification at the household level, and the options opened up for mutual transfers of material and immaterial resources may be the outcomes of all translocal (and not just transnational) systems resulting from mobility patterns (Frayne 2005; Long 2008; Mohapatra et al. 2009). The absence of qualifiers to the reference to "migrants" in the framework text (for example, "international", "forced/ voluntary", and even more so "environmental") is therefore key to making sure to look at all different groups, their specific conditions of vulnerability, and their resiliencebuilding potential for the communities and societies of origin and destination. This requires further analysis to understand the specific vulnerability features and capacities of individual migrants and their groups in any given context, and to determine what measures may be most appropriate to reduce their levels of risk.

In increasingly diverse societies, including migrants in DRR and disaster risk management (DRM) efforts is essential both to reducing the overall impacts of hazards and to harnessing all available resources to prevent, cope with, and recover from disasters. Moreover, the three references (and in particular Paragraph 7) seem broad enough to reflect the need to look at migrants in the context of all DRR efforts, including those that aim to reduce vulnerability and build resilience by targeting the more structural drivers of poverty and marginalization in predisaster times, currently included in the SFDRR Priority 3 of the Priorities for Action.

A specific reference to facilitating the transfer of remittances as a tool for building resilience and supporting recovery after disasters was discussed but not included in the final text; however, remittance transfers are among migrants' main ways to contribute to home households' and communities' well-being, and are arguably captured by the formulation of Paragraph 36(a)(vi).

Options for DRR Work A variety of stakeholders in migrants' societies of origin and destination have been carrying out a variety of efforts that could guide the operationalization of the mentioned SFDRR provisions.

(1) Areas of destination Access to basic services, formal employment opportunities, safe housing options, and adequate representation in local decision-making processes are all essential to addressing the underlying factors of migrants' vulnerability to disasters. A variety of initiatives exist at national and local levels to improve migrants' daily living conditions through more inclusive service provision 
and citizenship (Juzwiak et al. 2014), and are often necessary to address some of the key structural risk drivers most relevant to migrant groups.

Integrating attention to migrants and their social, economic, and cultural specificities in disaster risk management can help address some of the most immediate drivers of their vulnerability to disasters. Migrants, their organizations and representatives actively participate in disaster management work (Shepherd and Van Vuuren 2014). Policies and initiatives that support their engagement (through volunteering, hiring as staff, consultative mechanisms, and so on) may help risk management institutions to better profile the communities they serve, and plan for and carry out more inclusive preparedness, response, and recovery work (Martinez et al. 2009; Christchurch City Council 2012).

Disaster risk management institutions have a variety of options to address the specific barriers migrants face before, during, and after disasters. Migrants' awareness of local hazards and risk management structures and procedures, and their access to information and warnings, can be fostered by developing translated, understandable, and culturally appropriate communications and setting up targeted outreach systems that leverage a variety of nontraditional channels (for example, minority media, targeted workshops, door-to-door communication) (Hyogo Prefecture Emergency Net n.d.; Tochigi International Association n.d.; Benavides 2013). Migrants' access to disaster mitigation and assistance can be facilitated by removing migration status-based barriers to resources and services, including by softening the enforcement of migration regulations and simplifying procedures for issuing documentation, visa, and permits in disaster situations (post-Sandy immigration regulations, for example; USCIS 2012).

While these interventions are relatively well established in disaster risk management systems around the world, a number of key areas remain critical for their effectiveness. Migrants often live in spatially and culturally segregated communities, which reduced their access to external networks and resources. In addition, they might be reluctant to look for assistance regardless of their actual entitlement to access resources (Bolin 2006; Make the Road New York 2012). This is especially the case for migrants who have reasons not to trust host communities and authorities (marginalized groups and undocumented migrants, for example). Efforts to improve migrants' access to resources, information, and assistance need to be supported by longer-term awareness raising and trustbuilding work with their host communities and key authorities (for example, the police and basic service providers) (Farrow et al. 2009). It is particularly important to make sure that migrants are adequately assisted throughout the recovery phase because nationality and legal status tend to play a much bigger role as conditions for the provision of long-term public assistance than for the provision of life-saving services. Migrants are often not eligible for employment and reconstruction assistance, and might require specific protection against impoverishment, abuses, and exploitation in the aftermath of disasters (Venet 2006).

In addition to these efforts, migration can be leveraged to support a broader set of risk reduction goals in less traditional ways. Facilitating the migration of people from at-risk or disaster-affected areas can help support risk reduction, relief, and recovery efforts for households and communities back home (Rinke 2012), for example through instruments such as the US Temporary Protected Status (World Bank 2010). Reducing remittance costs in the aftermath of disasters seems to be a practice increasingly called for, and adopted by, relevant private sector actors, in order to support (early) recovery (Le De et al. 2015; Sathish 2015). Making sure that migrants are able to go back to their disaster-affected areas of origin can also be key to providing manpower, economic resources, and emotional support that speed up relief and recovery efforts (Chaudhary 2015). Lastly, migrants' knowledge can be leveraged in support of institutional or community-based resilience-building efforts benefitting their areas of origin. These so-called codevelopment practices also have the potential to empower migrants and increase their participation and representation in decision-making processes in areas of destination (Sall 2005; Østergaard-Nielsen 2011).

(2) Areas of origin Migrants' everyday safety and security can be greatly improved through the support of adequate standards and practices for recruitment and movement by the institutions of their countries of origin, as well as by providing them with information on hazards and risk management procedures in areas of destination before they depart (Congress of the Philippines 2009; Government of Nepal 2014). Building the capacity of consular systems to support nationals affected by disasters while abroad, and to directly engage in response and recovery efforts in the migrants' destinations can help complement the assistance migrants are able to access through host response systems in case of disasters (NAO 2005).

Involving diasporas in the design, financing, and implementation of resilience-building and risk reduction, as well as post-disaster relief and recovery, can allow households, communities, and institutions to tap into additional resources (SEDESOL n.d.; World Bank 2010). This is not limited to financial resources; members of the diaspora can be engaged to contribute their skills to risk reduction and resilience-building work, including through schemes to support their return (IOM Netherlands 2015). 
In addition, promoting channels for voluntary migration out of areas at risk or affected by disasters can help communities manage environmental risk and diversify available resources, ultimately strengthening their resilience (Abiola et al. 2005; Rinke 2012).

\section{Adapting Land Use Policy and Urban Planning to Demographic Change}

The role population movements can play as a compounding factor of risk is implicitly captured by the SFDRR text in two paragraphs:

Paragraph 6: [...] More dedicated action needs to be focused on tackling underlying disaster risk drivers, such as [...] demographic change [...] (UNISDR 2015a, p. 10).

Paragraph 30(f): Promote the mainstreaming of disaster risk assessments into land-use policy development and implementation, [...] and the use of guidelines and follow-up tools informed by anticipated demographic and environmental changes (UNISDR 2015a, p. 19).

Human mobility is one of the key drivers of global and local demographic change. The overwhelming majority of population movements is directed toward cities, contributing to their physical expansion and socioeconomic diversification (IOM 2015b). Factoring present and expected population movements into urban development and service delivery should therefore be a key component of creating more inclusive and resilient settlements.

Options for DRR Work Mainstreaming migration into urban planning requires looking into both the mobility effects of planning decisions and the planning implications of accommodating demographic changes linked to migration. Land use, its changes, infrastructural developments, and, more in general, investments, both in urban areas and in more or less distant locations produce changes in people's distribution and mobility. These effects need to be understood and taken into account to make sure institutions and markets have sufficient capacity to meet cities' needs in terms of housing and infrastructure, essential services, and opportunities. This can be done, for instance, through quantitative assessments and scenarios that estimate incoming and outgoing population flows as a consequence of urban development and investments, and inform planning choices for local authorities and markets (IOM 2015c; Lee and Holme 2015). This also requires promoting the use of tools to understand existing and future cultural diversity in a city area, and that allow planning for the delivery of culturally appropriate services to a shifting demographic reality (Robinson 2015).

\section{Managing Relocations to Reduce Disaster Risk}

Relocations, planned population movements in which people or communities are assisted (usually by an institutional actor) to move, settle, and rebuild their lives in a new location, are highlighted in the SFDRR as a potential option to reduce risk:

Paragraph 27(k): Formulate public policies, where applicable, aimed at addressing the issues of prevention or relocation, where possible, of human settlements in disaster risk zones, subject to national law and legal systems (UNISDR 2015a, p. 18).

Relocations have received specific attention because of growing concerns for increasing hazard incidence in, and potential inhabitability of, whole areas as a consequence of environmental change-for example, loss of land and key natural resources and increased coastal hazards on lowlying islands and in low-elevation coastal zones (Bronen 2014) — and are the object of dedicated initiatives (Brookings Institution n.d.). Supporting people to resettle out of at-risk areas can drastically reduce their exposure and vulnerability, and might be regarded as the only option available to reduce risk in areas highly exposed to hazards or undergoing irreversible environmental degradation. However, relocations are complex and costly processes that have the potential to deplete the human, social, and economic capital of relocated persons, their hosts, and the communities left behind.

Options for DRR Work Successful relocations require that a variety of different elements be taken into account beyond the physical movement of people, requiring longterm engagement by the supporting institutions. This is best based on clear legal frameworks and transparent decision making that balances all costs and benefits, as well as on comprehensive assessment and monitoring of environmental and socioeconomic conditions in areas of origin and destination. This information is key for making decisions on whether, when, and where to relocate a given community (Bronen 2015). Maintaining, or if possible, improving access to land and property, livelihood opportunities (including through trainings, cash disbursements, and distribution of tools), housing and services for those being relocated, their host communities, and those being left behind is a precondition for strengthening people's wellbeing and security through the relocation process and to prevent the process from resulting in impoverishment, conflicts, tensions, and possibly from failing completely 
(Trung Son Hydropower 2009; Oliver-Smith and de Sherbinin 2014; Chun 2015).

Such efforts are best supported by participatory mechanisms for planning and decision making that include those being relocated, as well as host communities and individuals in locations of origin that are not participating in the relocation (Mitchell 2015).

\section{Preparing for and Managing Evacuations and Displacement}

A number of SFDRR paragraphs point to disaster-induced evacuations and displacement as a key issue for DRR:

Paragraph 33(h): Promote regular disaster preparedness, response and recovery exercises, including evacuation drills, training and the establishment of area-based support systems, with a view to ensuring rapid and effective response to disasters and related displacement, including access to safe shelter, essential food and non-food relief supplies, as appropriate to local needs (UNISDR 2015a, p. 21).

Paragraph 33(m): Strengthen the capacity of local authorities to evacuate persons living in disasterprone areas (UNISDR 2015a, p. 22).

Paragraph 28(d): Promote transboundary cooperation to enable policy and planning for the implementation of ecosystem-based approaches with regard to shared resources, such as within river basins and along coastlines, to build resilience and reduce disaster risk, including epidemic and displacement risk (UNISDR 2015a, p. 18).

Paragraph 33(j): [...] Integrate post-disaster reconstruction into the economic and social sustainable development of affected areas. This should also apply to temporary settlements for persons displaced by disaster (UNISDR 2015a, p. 22).

In the face of impending disasters, moving is a lifesaving strategy. Fleeing, before or after a hazard strikes, as part of planned, well-managed evacuations or of more spontaneous flows, is key to reducing the human consequences of hazards. Effective evacuations have allowed for a significant reduction of mortality from disasters for which forecast is possible during the implementation period of the HFA (UNISDR 2015b).

Evacuations are normally assumed to be short-lived. However, the extent of a hazard's impacts, the lack of adequate responses, and individual conditions of vulnerability can result in the displacement of affected persons for much longer periods. In such cases the net result of moving can be to disrupt access to a series of key assets and opportunities, and result in insufficient access to basic services and livelihood options, impoverishment, and increased exposure to violence and insecurity for both the displaced populations and their host communities (Sherwood et al. 2014, 2015). Such effects are among the most significant indirect impacts of hazards, and, if left unaddressed, have the potential to multiply, spatially extend, and turn disaster losses into a chronic condition (Esnard and Sapat 2014). With almost 200 million people forced to move as a consequence of sudden-onset natural hazards over the last 6 years (IDMC 2015), management of disaster-induced population movements has emerged as a priority for DRM actors all over the world.

Despite the clear recognition of this fact-highlighted in the SFDRR Preamble (UNISDR 2015a, p. 9), the SFDRR is weaker on this point than its zero [Paragraph 31(a)] and pre-zero draft [Paragraph 16(d)] texts, both of which included more targeted provisions on preparing for and addressing displacement as a core element of disaster risk management (and more specifically recovery) efforts. This was due to the strong opposition of some countries to discussing potentially sensitive issues such as displacement and durable solutions.

Interestingly, though, the reference to displacement as a transboundary risk has not been the object of significant debate throughout the consultations, despite its relatively limited relevance within the broader spectrum of disasterinduced movements (IDMC 2015) and its potentially more politically sensitive implications. This might have been the result of successful and more targeted advocacy work under the Nansen Initiative, which has been building consensus around a protection agenda for people looking for assistance and protection outside their countries of origin as a consequence of disasters and environmental change, largely in parallel with the pre-Sendai consultations. ${ }^{5}$

Options for DRR Work Risk management laws, policies, and plans identifying roles and responsibilities for all actors involved in early warning and disaster response, as well as the mechanisms for their coordination, provide the basis for much of the work of preparing for and managing evacuations and displacement. Making sure that mobility in disaster and displacement after disasters are seen as core components of such documents and frameworks is a precondition for effective disaster preparedness and response (CCCM Cluster 2014). Understanding people's movements in disasters, by setting up systems to track disaster-induced population movements, into and out of formal and informal displacement sites, as well as profiling affected persons and their host communities, is key to effective delivery of

\footnotetext{
${ }^{5}$ https://www.nanseninitiative.org.
} 
services and assistance (Yonetani and Yuen 2014). As people's movement in times of disasters (in particular those associated with sudden-onset hazards), while intense and concentrated, often follows similar trajectories to normaltime movements, understanding predisaster mobility can help better plan for future disasters (Xin et al. 2012).

In the management of evacuations and displacement situations, it is necessary to look at the different needs of particular groups and individuals-physical and cultural characteristics, gender, income, migration status, and ethnicity influence people's willingness and capacity to evacuate, and seek and accept assistance (IASC 2011). Such differences should be kept in mind when identifying safe evacuation routes and sites, to minimize the risk of people being trapped in disaster-affected areas (Laska and Morrow 2006; Black et al. 2012). But they are also key when planning sites for use and when assisting displaced persons within and outside displacement sites (IOM and Government of Nepal 2011; Maribyrnong City Council n.d.). Setting up systems that allow affected persons to provide feedback can help better identify and address the variety of their needs.

In the specific case of disaster-induced, cross-border displacement, reviewing existing migration frameworks in order to integrate provisions for the entry and stay of persons displaced by disasters can help support people's mobility and access to assistance (Cantor 2014). In addition, promoting joint contingency planning and emergency response among disaster management institutions, civil protection agencies, service providers, and communities, in particular in border areas characterized by intense population circulation, can help effectively provide assistance to those displaced across borders (INGC et al. 2013).

\section{Sustainably Addressing Disaster-Induced Human Mobility}

The SFDRR includes a broader reference to the need to address all disaster-induced movements with the aim to build resilience:

Paragraph 30(1): Encourage the adoption of policies and programmes addressing disaster-induced human mobility to strengthen the resilience of affected people and that of host communities as per national laws and circumstances (UNISDR 2015a, p. 20).

People move in a variety of ways before, during and after sudden-onset and slow-onset disasters, ranging from short-term evacuations to permanent, long-distance migration (Esnard and Sapat 2014; Yonetani and Yuen 2014). The SFDRR acknowledges that all these movements can result in increased vulnerability for those moving, as well as in increased pressures on host communities and ecosystems. Addressing the full spectrum of mobility patterns resulting from disasters with the aim of building the resilience of all the people directly and indirectly affected by such movements is fundamental to reducing the longerterm and longer-distance impacts of hazards. Resolving situations of vulnerability revealed by, and resulting from, displacement is a key component of recovery efforts that aim to build back safer communities. In the light of the narrower scope of the relevant provision of the Paris Agreement (UN 2015b, Paragraph 50), which refers to climate-induced displacement only, the SFDRR provision could represent the basis for more comprehensive, and ultimately just and inclusive, efforts to address this issue.

Options for DRR Work Understanding normal time mobility patterns and trajectories can provide useful insights for interpreting mobility in the context of disasters (Xin et al. 2012). Addressing disaster-induced mobility to promote resilience requires understanding how moving is part of household-level coping strategies in anticipation of and in response to environmental shocks and stresses (Scheffran et al. 2012), and it implies looking at the potential of promoting (further) mobility, of affected households or some of their members, as a possible option for achieving safer living conditions and better access to resources and opportunities (Murray and Williamson 2011). This complements traditional options for addressing displacement through voluntary return, local integration, and relocation of people out of disaster affected areas (IASC 2011).

Such resilience building efforts require particular attention to addressing host communities' preexisting vulnerabilities as part of the process of ensuring adequate living conditions for those on the move (Sherwood et al. 2014), reducing environmental impacts of population inflows (Berry 2008), and promoting community cohesion among newcomers and host communities (Esnard and Sapat 2014). Legal frameworks and planning can provide a basis for integrating attention to addressing population movements as part of post-disaster work (Sherwood et al. 2015).

\section{Conclusions}

Despite the political sensitivity of topics such as migration and displacement and the reticence of a part of the Member States to discuss them at all in a DRR policy forum, the SFDRR adopted a much more nuanced view on population movements and their effects on risk creation and reduction than the HFA did. As a consequence, the SFDRR gives consideration to a variety of human mobility issues that are extremely relevant for DRR work-leaving, however, unaddressed a few crucial issues. 
The notion that migrants and displaced persons might present specific conditions of vulnerability in the face of disasters seemed to be well established from the outset of the Sendai preparatory process; however, mobility status (for example, internal/international migrant or displaced, documented/undocumented) was excluded, upon discussion, from the criteria for disaggregation of risk and loss data [currently Paragraph 19(g)]. This seemed to be due to the Member States' unwillingness to commit to the implementation of a potentially challenging provision, given that mobility status information is not traditionally included in disaster-related data collection efforts, and that what records exist of migrants' and displaced persons' presence at national and local levels may be incomplete, difficult to keep up-to-date, and sensitive. Despite existing anecdotal evidence, the specific impacts of disasters on migrants are not systematically recorded, which is both cause and consequence of their "invisibility" in many disaster risk reduction and management systems. It is interesting to note, however, that migration status is part of the disaggregation criteria required by the SDG follow-up and review processes (UN 2015a, Paragraph 74.g), including for the goals that refer to disaster impacts, risk reduction, and resilience building (UN 2015a, Paragraph 59, Goals 1.5 and 11.5).

The lack of risk and loss data disaggregated by mobility status is an obstacle to understanding how different types of movement (for example, internal or cross-border, documented or undocumented) interact with other characteristics (such as gender, age, ethnicity, race, income, and employment status) in producing vulnerability. Throughout the SFDRR text, "migrants" seems to be used as an umbrella term, hiding a variety of individual, collective, and systemic circumstances that shape different forms and degrees of vulnerability and might need to be addressed through different measures.

The idea that migrants do contribute to building the resilience of home and host communities was increasingly accepted throughout the consultations. Remittance transfers are probably the main element literature and practice on migration and development look at in this regard (for an overview, see UNDP 2009). However, facilitating remittance flows as an option to support household-led resilience building was strongly opposed, mainly based on concerns by a few countries that such measures would infringe on private choices and initiatives related to the allocation of privately earned funds for the achievement of individual and household-level goals. This opposition was somewhat surprising in the light of the centrality that measures to facilitate remittance transfers have had in the SDG discussions. The SDG's target 10.c (UN 2015a) explicitly calls for the reduction of costs associated with remittance transfers- going very much in the direction that was envisaged in the proposed SFDRR text.

While displacement is highlighted as one of the main consequences of disasters, the need to take practical steps to prepare for, respond to, and address this issue as a key part of risk management efforts has been largely toned down through the SFDRR drafting process. This was possibly due to the perceived political sensitivity of the topic, in particular when "displacement" was not explicitly referred to as disaster-induced movements, leaving some confusion on the possible inclusion of movements triggered by violence or conflict in the SFDRR provisions.

Recognition of human mobility as one of the determinants of risk at the global and local levels is only implicit (under the umbrella of "demographic change"). In particular, there is no reference to the need to make sure that mobility choices and trajectories take place under legal and practical conditions that minimize potential disaster risk outcomes. The text proposed in this regard was reworked throughout the negotiations to refer to the management of disaster-induced movements alone (UNISDR 2015a, Paragraph 30(1)), regardless of the fact that any kind of population movement influences hazard exposure, vulnerability, and resilience (IOM 2015a). This might be an indication of a lack of capacity or willingness to address underlying, structural drivers of risk as part of DRR policy and operational efforts. However, as much as the management of disaster-related movements is a core element of risk management, the integration of a risk reduction perspective in any policy, measure, or decision influencing human mobility patterns should be understood as a precondition to prevent the production of vulnerability and risk.

Despite these shortcomings, the SFDRR gives consideration to a number of human mobility issues that are extremely relevant for DRR, and provides a platform for a variety of actions that might be key to reducing the impacts of hazards over the next decades, a period in which population flows are expected to remain intense (UNDESA 2013). Moreover, the SFDRR explicitly highlights several operational priorities that could also be at the heart of sustainable development and climate change adaptation efforts, and that have not been unpacked in such detail in higher-level documents such as the resolution on the SDGs or the UNFCCC Paris Agreement. This might be, in particular, a case for the newly established task force on displacement related to the adverse impacts of climate change (UN 2015b, Paragraph 50), whose work, whatever it will actually encompass, will have to draw upon experiences and efforts in risk reduction, disaster management, and disaster recovery.

The operationalization of the mobility-related provisions of the SFDRR points to a broad set of measures that may contribute to reducing the impacts of hazards and strengthening people's resilience. Prioritization of actions 
will largely depend on context-specific variables and existing local capacities. In today's diverse societies it is likely that migrant-inclusive DRM efforts will play an increasing role in reducing overall losses to disasters. With disaster-induced displacement involving more people around the world, measures to anticipate, manage, and address this displacement are likely to become even more important to disaster preparedness, response, and recovery. Relocations might become a somewhat more common option to face the impacts of environmental change.

More fundamentally, however, we seem to be heading into an era of increased local, regional, and global mobility. Making sure that these movements take place in ways that do not result in further risk, in particular for those who are already more marginalized and excluded, might be the most urgent priority of all. Improved integration of risk reduction and human mobility perspectives will be essential to achieving the objectives of the SFDRR, as well as to promoting the well-being and security of those moving, those hosting them, and those staying behind over the next decades.

Open Access This article is distributed under the terms of the Creative Commons Attribution 4.0 International License (http://creative commons.org/licenses/by/4.0/), which permits unrestricted use, distribution, and reproduction in any medium, provided you give appropriate credit to the original author(s) and the source, provide a link to the Creative Commons license, and indicate if changes were made.

\section{References}

Abiola, F.A., A. Teko-Agbo, C. Biaou, and M. Niang. 2005. Socioeconomic and animal health impact of transhumance. Conference OIE 2005: 105-119. http://www.oie.int/doc/ged/d3248.pdf. Accessed 17 Feb 2016.

Benavides, A.D. 2013. Four major disaster occurrences and the Spanish language media: A lack of risk communication. Disaster Prevention and Management 22(1): 29-37.

Berry, L. 2008. The impact of environmental degradation on refugeehost relations: A case study from Tanzania. Research Paper No. 151, Geneva: The UN Refugee Agency. http://www.unhcr.org/ 47a315c72.pdf. Accessed 17 Feb 2016.

Black, R., N.W. Arnell, W.N. Adger, D. Thomas, and A. Geddes. 2012. Migration, immobility and displacement outcomes following extreme events. Environmental Science \& Policy 27(S1): S32-S43.

Bolin, B. 2006. Race, class, ethnicity, and disaster vulnerability. In Handbook of disaster research, ed. H. Rodriguez, E.L. Quarantelli, and R.R. Dynes, 113-129. New York: Springer.

Bronen, R. 2014. Community relocations: The Arctic and South Pacific. In Humanitarian crises and migration: Causes, consequences and responses, ed. S. Martin, S. Weerasinghe, and $\mathrm{A}$. Taylor, 221-242. Abingdon: Routledge.

Bronen, R. 2015. Climate-induced community relocations: Using integrated social-ecological assessments to foster adaptation and resilience. Ecology and Society 20(3): 36. doi:10.5751/ES07801-200336.

Brookings Institution. n.d. Planned relocations, disasters, and environmental change (including climate change). http://www. brookings.edu/about/projects/idp/planned-relocations. Accessed 17 Feb 2016.

Cantor, D.J. 2014. Law, policy and practice concerning the humanitarian protection of aliens on a temporary basis in the context of disasters: States of the regional conference on migration and others in the Americas. Geneva: Nansen Initiative.

Castles, S., and M.J. Miller. 2009. The age of migration: International population movements in the modern world, 4th edn. Basingstoke: Palgrave MacMillan.

CCCM (Camp Coordination and Camp Management) Cluster. 2014. The MEND guide: Comprehensive guide for planning mass evacuations in natural disasters. Geneva: Camp Coordination and Camp Management Cluster. http://www.globalcccmcluster. org/system/files/publications/MEND_download.pdf. Accessed 17 Feb 2016.

Chaudhary, V. 2015. Qatar refuses to let Nepalese workers return to attend funerals after quake. The Guardian. 24 May 2015. http://www. theguardian.com/world/2015/may/24/qatar-denies-nepalese-worldcup-workers-leave-after-earthquakes. Accessed 17 Feb 2016.

Christchurch City Council. 2012. Best practice guidelines: Engaging with culturally and linguistically diverse $(C A L D)$ communities in times of disaster. Christchurch: Christchurch City Council.

Chun, J. 2015. Planned relocations in the Mekong Delta: A successful model for climate change adaptation, a cautionary tale, or both? Washington, DC: The Brookings Institution.

Congress of the Philippines. 2009. Republic act 10022, The Philippines. http://www.lawphil.net/statutes/repacts/ra2010/ra_10022 2010.html. Accessed 17 Feb 2016.

Esnard, A.M., and A. Sapat. 2014. Displaced by disaster: Recovery and resilience in a globalizing world. New York: Routledge.

Farrow, D., A. Rutter, and R. Hurworth. 2009. Evaluation of the inclusive emergency management with CALD communities program. Melbourne: Centre for Program Evaluation, The University of Melbourne.

Frayne, B. 2005. Survival of the poorest: Migration and food security in Namibia. In Agropolis: The social, political and environmental dimensions of urban agriculture, ed. L.J.A. Mougeot, 31-50. London: Earthscan.

Government of Nepal. 2014. Labour migration for employment: A status report for Nepal: 2013/2014. Kathmandu: Government of Nepal, Department of Foreign Employment. https://asiafounda tion.org/resources/pdfs/MigrationReportbyGovernmentofNepal. pdf. Accessed 17 Feb 2016.

Hyogo Prefecture Emergency Net. n.d. Multi-lingual emergency information system. http://bosai.net/e/index.do. Accessed 17 Feb 2016.

IASC (Inter-Agency Standing Committee). 2011. IASC framework on durable solutions for internally displaced persons. Washington, DC: The Brookings Institution.

IDMC (Internal Displacement Monitoring Centre). 2015. Global estimates 2015: People displaced by disasters. Geneva: Internal Displacement Monitoring Centre.

IDMC (Internal Displacement Monitoring Centre). n.d. Global figures. http://www.internal-displacement.org/global-figures. Accessed 17 Feb 2016.

INGC (Instituto Nacional de Gestão das Calamidades), Government of Botswana, Government of Namibia, IOM (International Organization for Migration). 2013. Training of trainers report: Capacity building as a disaster preparedness measure, reducing risk of population displacement in Southern Africa. Maputo: International Organization for Migration.

IOM (International Organization for Migration). 2013. Compendium of IOM's activities on disaster risk reduction and resilience. Geneva: International Organization for Migration.

IOM (International Organization for Migration). 2015a. Human mobility: Shaping vulnerability and resilience to disasters. 
Geneva: International Organization for Migration. http://www. iom.int/files/live/sites/iom/files/What-We-Do/docs/backgroundpaper-for-HFA2-light.pdf. Accessed 17 Feb 2016.

IOM (International Organization for Migration). 2015b. World migration report 2015. Geneva: International Organization for Migration.

IOM (International Organization for Migration). 2015c. Mainstreaming migration at the local level: The case of Naga City, Philippines. Manila: International Organization for Migration. https://www.gfmd.org/files/documents/Mainstreaming_migration_ in_Naga_City_Philippines.pdf. Accessed 17 Feb 2016.

IOM (International Organization for Migration) Netherlands. 2015. Temporary return of qualified nationals (TRQN III). http://www. iom-nederland.nl/en/migration-and-development/81-migrationand-development/88-temporary-return-of-qualified-nationalstrqn-ii. Accessed 17 Feb 2016.

IOM (International Organization for Migration) and Government of Nepal. 2011. Report on identification of open spaces for humanitarian purposes in Kathmandu Valley. Kathmandu: International Organization for Migration and Government of Nepal, Ministry of Home Affairs.

Juzwiak, T., E. McGregor, and M. Siegel. 2014. Migrant and refugee integration in global cities, the role of cities and business. The Hague: The Hague Process on Refugees and Migration.

Kelman, I. 2015. Climate change and the Sendai framework for disaster risk reduction. International Journal of Disaster Risk Science 6(2): 117-127.

Koser, K. 2014. Protecting non citizens in situations of conflict, violence and disaster. In Humanitarian crises and migration: Causes, consequences and responses, ed. S. Martin, S. Weerasinghe, and A. Taylor, 267-286. Abingdon: Routledge.

Laska, S., and B. Morrow. 2006. Social vulnerabilities and Hurricane Katrina: An unnatural disaster in New Orleans. Marine Technology Society Journal 40(3): 7-17.

Le De, L., J.C. Gaillard, W. Friesen, and F. Matautia Smith. 2015. Remittances in the face of disasters: A case study of rural Samoa. Environment, Development and Sustainability 17(3): 653-672.

Lee, M., and P. Holme. 2015. Relating land use and human intra-city mobility. PLoS ONE 10(10): e0140152.

Long, N. 2008. Translocal livelihoods, networks of family and community and remittances in central Peru. In Migration and development across borders: Research and policy perspectives on internal and international migration, ed. J. DeWind, and J. Holdaway, 37-68. Geneva and New York: International Organization for Migration and Social Science Research Council.

Make the Road New York. 2012. Unmet needs: Superstorm Sandy and immigrant communities in the metro New York area. New York: Make the Road New York.

Maribyrnong City Council. n.d. Emergency relief (evacuation) centres management guidelines for CALD groups. Maribyrnong, Victoria.

Martinez, A., A. Hoff, and A. Núñez-Alvarez. 2009. Coming out of the dark: Emergency preparedness plan for farmworkers in San Diego County. San Marcos: National Latino Research Center, California State University. https://www.csusm.edu/nlrc/docu ments/report_archives/FW\%20Emergency\%20Plan\%205\%2017 \%2010.pdf. Accessed 17 Feb 2016.

Mitchell, M. 2015. Relocation after disaster: Engaging with insured residential property owners in Greater Christchurch's landdamaged "residential red zone". Washington, DC: The Brookings Institution.

Mohapatra, S., G. Joseph, and D. Ratha. 2009. Remittances and natural disasters: Ex-post response and contribution to ex-ante preparedness. Washington, DC: The World Bank.

Murray, R., and S.P. Williamson. 2011. Migration as a tool for disaster recovery: A case study on U.S. policy options for post- earthquake Haiti. Working Paper 255, Washington, DC: Centre for Global Development. http://www.cgdev.org/sites/default/ files/1425143_file_Murray_Williamson_disaster_recovery_FINAL. pdf. Accessed 17 Feb 2016.

NAO (National Audit Office). 2005. Consular services to British nationals. London: National Audit Office.

Oliver-Smith, A., and A. de Sherbinin. 2014. Resettlement in the twenty-first century. Forced Migration Review 45: 23-25.

Østergaard-Nielsen, E. 2011. Codevelopment and citizenship: The nexus between policies on local migrant incorporation and migrant transnational practices in Spain. Ethnic and Racial Studies 34(1): 20-39.

Rinke, T. 2012. Temporary and circular labor migration between Spain and Colombia. In The state of environmental migration 2011, ed. F. Gemenne, P. Brücker, and D. Ionesco, 25-34. Paris and Geneva: Institute for Sustainable Development and International Relations and International Organization for Migration.

Robinson, D. 2015. Resilience and immigration: A Bristol perspective. Presentation at the Big Ideas Webinar "Migration and the Resilient City: Bristol". http://citiesofmigration.ca/webinar/resi lientcity/. Accessed 17 Feb 2016.

Sall, B. 2005. Migration, remittances and economic initiatives in SubSaharan Africa. In Migration, remittances and development, 265-278. Paris: OECD Publishing.

Sathish, V.M. 2015. UAE exchange waives fee on Nepal remittances. Emirates News 24/7, 29 April 2015. http://www.emirates247.com/ news/emirates/uae-exchange-waives-fee-on-nepal-remittances2015-04-29-1.589056. Accessed 17 Feb 2016.

Scheffran, J., E. Marmer, and P. Sow. 2012. Migration as a contribution to resilience and innovation in climate adaptation: Social networks and co-development in northwest Africa. Applied Geography 33: 119-127.

SEDESOL (Secretaria de Desarrollo Social Mexico). n.d. 3x1 para migrantes. http://www.3x1.sedesol.gob.mx/. Accessed $17 \mathrm{Feb}$ 2016.

Shepherd, J., and K. van Vuuren. 2014. The Brisbane flood: CALD gatekeepers' risk communication role. Disaster Prevention and Management 23(4): 469-483.

Sherwood, A., M. Bradley, L. Rossi, R. Gitau, and B. Mellicker. 2014. Supporting durable solutions to urban, post-disaster displacement: Challenges and opportunities in Haiti. Washington, DC and Geneva: The Brookings Institution and International Organization for Migration.

Sherwood, A., M. Bradley, L. Rossi, R. Gitau, and B. Mellicker. 2015. Resolving post-disaster displacement: Insights from the Philippines after Typhoon Haiyan (Yolanda). Washington, DC and Geneva: The Brookings Institution and International Organization for Migration.

Tacoli, C. 2013. Migration as a response to local and global transformations: A typology of mobility in the context of climate change. In The demography of adaptation to climate change, ed. G. Martine, and D. Schensul, 41-54. New York, London and Mexico City: United Nations Population Fund, International Institute for Environment and Development and El Colegio de México

Tochigi International Association. n.d. Disaster prevention information for foreign residents. http://tia21.or.jp/disaster_eng.html. Accessed 17 Feb 2016.

Trung Son Hydropower. 2009. Resettlement livelihoods and ethnic minorities development program. http://siteresources.worldbank. org/INTVIETNAM/Resources/TrungSonRLDPmainreportfordi sclosure.pdf. Accessed 17 Feb 2016.

UN (United Nations). 2015a. Transforming our world: The 2030 agenda for sustainable development. A/RES/70/1. http://www.un.org/ga/ search/view_doc.asp?symbol=A/RES/70/1\&Lang=E. Accessed 17 Feb 2016. 
UN (United Nations). 2015b. Adoption of the Paris agreement. FCCC/CP/2015/L.9/Rev.1. http://unfccc.int/resource/docs/2015/ cop21/eng/109.pdf. Accessed 17 Feb 2016.

UNDESA (United Nations Department of Economic and Social Affairs). 2013. International migration report 2013. New York: United Nations. http://www.un.org/en/development/desa/popula tion/publications/pdf/migration/migrationreport2013/Full_Docu ment_final.pdf. Accessed 17 Feb 2016.

UNDP (United Nations Development Programme). 2009. Human development report 2009: Overcoming barriers, human mobility and development. New York: United Nations.

UNISDR (United Nations International Strategy for Disaster Reduction). 2005. Hyogo framework for action 2005-2015. Geneva: United Nations.

UNISDR (United Nations International Strategy for Disaster Reduction). 2015a. Sendai framework for disaster risk reduction 20152030. Geneva: United Nations. http://www.preventionweb.net/ files/43291_sendaiframeworkfordrren.pdf. Accessed 17 Feb 2016.

UNISDR (United Nations International Strategy for Disaster Reduction). 2015b. Global assessment report 2015. Geneva: United Nations.

USCIS (U.S. Citizenship and Immigration Services). 2012. USCIS reminds individuals affected by Hurricane Sandy of temporary immigration relief measures. Press note. U.S. Citizenship and Immigration Services. http://www.uscis.gov/humanitarian/specialsituations/previous-special-situations/uscis-reminds-individuals- affected-hurricane-sandy-temporary-immigration-relief-measures. Accessed 17 Feb 2016.

Venet, F. 2006. Assistance to migrants during and after the emergency and access to employment opportunities (Atención a migrantes durante y después de la emergencia y oportunidad de acceso de trabajo). Seminario Taller Internacional, Riesgo de desastres y migración. Propuestas para el abordaje de la problema. Grupo Guatemala México Migración Y Desarrollo.

Weerasinghe, S., and A. Taylor. 2015. On the margins: Noncitizens caught in countries experiencing violence, conflict and disaster. Journal on Migration and Human Security 3(1): 26-57.

World Bank. 2010. Haiti remittances key to earthquake recovery. http:// www.worldbank.org/en/news/feature/2010/05/17/haiti-remittanceskey-to-earthquake-recovery. Accessed 17 Feb 2016.

Xin, L., L. Bengtsson, and P. Holme. 2012. Predictability of population displacement after the 2010 Haiti earthquake. PNAS 1009(29): 11570-11581.

Yonetani, M., and L. Yuen. 2014. The evolving picture of displacement in the wake of Typhoon Haiyan: An evidence-based overview. Manila: Government of the Philippines, Department of Social Welfare and Development, International Organization for Migration, Internal Displacement Monitoring Centre and SAS. http://www.iom.int/files/live/sites/iom/files/Country/docs/TheEvolving-Picture-of-Displacement-in-the-Wake-of-TyphoonHaiyan.pdf. Accessed 17 Feb 2016. 